\title{
Liver Glycogenosis and Cataracts in a Mentally Deficient Child
}

\author{
I. DE LOORE and H. H. VAN GELDEREN \\ From the Children's Department, University Hospital, Leiden, The Netherlands
}

After van Creveld (1928) had given the first clinical description of a child with glycogenosis and suggested that the primary cause could be a disorder of glycogen metabolism, this hypothesis was confirmed. Six types have already been described, each of which show a different enzyme defect and a different clinical picture. By means of a simplified scheme of glycogen synthesis and breakdown, these types with their enzyme defects are set out below.

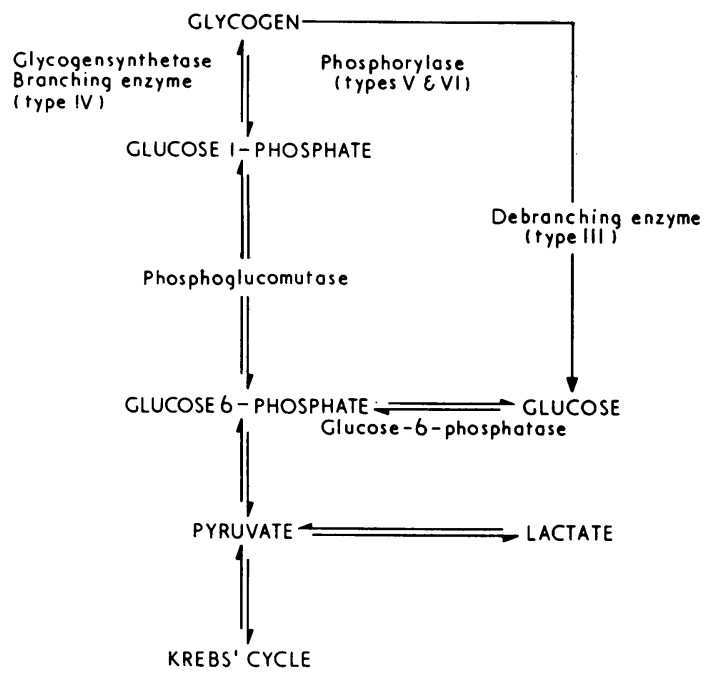

According to Cori's (1954) classification, modified by Brante, Kaijser, and Öckerman (1964), they are as follows. Type I: lack of glucose-6-phosphatase. Type III: lack of debranching enzyme. Type IV: lack of branching enzyme. Types V and VI: lack of muscle or liver phosphorylase, respectively. Type II: the enzyme defect in this form does not concern the energetic sphere of glycogen metabolism; according to Hers (1965) it is thought to be a lysosomal

Received October 17, 1966. defect, in which the hydrolysin $\alpha$-glucosidase is lacking.

In the past few years, however, more enzyme defects have been reported. Thomson, Maclaurin, and Prineas (1963) described a phosphoglucomutase deficiency in muscle, and Illingworth and Brown (1964) reported the same defect in muscle and liver. This enzyme deficiency is called by some the seventh type of glycogenosis.

In 1963 Lewis, Spencer-Peet, and Stewart described an inborn error of glycogen metabolism, which is accompanied by the clinical picture of glycogenosis, but in which liver glycogen is practically absent: lack of glycogensynthetase.

Recently Húg, Garancis, Schubert, and Kaplan (1966) reported that apart from enzyme deficiencies a faulty activation of enzyme systems may lead to glycogen storage disease. They described two patients with liver glycogenosis in which the activation system of liver phosphorylase was thought to be deficient in different ways.

As each patient showed a different clinical picture they called these forms of glycogenosis types VIII and IX.

Our paper reports a case of clinical, histological, and biochemical glycogenosis in a mentally deficient girl with bilateral cataracts.

\section{Case Report}

The patient, the sixth child of healthy parents, was born after a normal pregnancy, at term, birthweight $3000 \mathrm{~g}$. The fourth child had died during delivery; there had been no post-mortem examination but the outward appearance of the child was normal. The paternal grandfather and the maternal great grandmother were brother and sister. In other respects the family history yielded no significant data.

Shortly after birth blindess was suspected, and at the age of 6 weeks bilateral cataracts with deficient retinal function were diagnosed (Prof. Henkes, Rotterdam). At the age of $8 \frac{1}{2}$ months the patient was admitted to hospital because of acute dehydration and acidosis. This was at first thought to be caused by a urinary 
infection, but because the episodes recurred the patient was transferred to our department.

At this time she was 1 year old, in a reasonable nutritional state, and of normal height and weight. Growth subsequently remained normal. On examination there were bilateral cataracts. Discission was carried out nine times, and iridectomy twice (Prof. Colenbrander, Ophtalmology Department of the University Hospital, Leiden). There was, however, no improvement, and the patient is still blind. Hepatomegaly was present without splenomegaly: the liver edge was felt $3 \mathrm{~cm}$. below the ribs. Mental development was much retarded. Initial investigations showed that the acidotic attacks were often accompanied by a strong tendency to hypoglycaemia. During the second year these attacks occurred as soon as there was any deviation of the treatment regimen of frequent carbohydrate meals, as for example overnight fasts, mild upper respiratory infections, with skipping of 2 or 3 meals, or vomiting. This tendency to acidosis and also the treatment of cataracts made a nine months' stay in hospital inevitable. Thereafter the girl had to be readmitted seven times.

Because of the history of acidotic attacks with early urinary infections on the one hand, and the combination of hypoglycaemia and hepatomegaly on the other, investigations on both renal function and carbohydrate metabolism were undertaken.

Renal investigations. Up to the age of 2 years pyuria with positive cultures and slight albuminuria were occasionally found. Thereafter the urine remained normal, possibly because of long-term antibiotic therapy.

Investigation of kidney function showed normal concentration capacity; urine $p \mathrm{H}$ was usually between $6 \cdot 0$ and $7 \cdot 0$, when there was no infection. During acidotic attacks values between $5 \cdot 0$ and $6 \cdot 0$ were found. An acid test showed a slightly deficient ability to acidify urine, mainly determined by a somewhat limited ammonia formation. After three days of ammonium chloride load urine $p \mathrm{H}$ was $5 \cdot 5$, and the ammonium excretion $30 \mathrm{mEq} / 24 \mathrm{hr} . / \mathrm{m}^{2}$

Hydrogen ion clearance indexes were on the low side of normal. Urine was sterile at the time of investigation.

Urea and creatinine in blood and clearances of creatinine and phosphate were always normal.

As a rule amino acid excretion and amino acid chromotograms were normal. Only once did hyperaminoaciduria with lysinuria occur during an acidotic attack.

Intravenous pyelography at the age of 3 years showed normal excretion on both sides. The kidneys were normal in size, form, and position, but in both upper poles slightly malformed calices suggested pyelonephritic damage.

Cystoscopy and retrograde pyelography did not show anomalies.

Summarizing, our patient suffered from recurrent pyuria up to the age of 2 years. No congenital renal anomaly was found as a cause of the pyuria. The mild deficiency in the ability to acidify urine was not serious enough to explain the symptoms.
Investigation of carbohydrate metabolism. During periods of good health, values for calcium, phosphorus, phosphatase, protein, and protein electrophoresis, transaminases, bilirubin, thymol turbidity test, cholesterol, and total lipoid were normal. Blood values for lactic acid were $9 \mathrm{mg}$. and $11 \mathrm{mg} . / 100 \mathrm{ml}$., for pyruvate $1.7 \mathrm{mg} . / 100 \mathrm{ml}$, , and for insulin $6 \mu \mathrm{Eq}$ (normal between 3 and $9 \mu \mathrm{Eq})$.

Upon waking, urine often showed acetonuria, even when on a diet rich in carbohydrates.

The fasting level of blood sugar, on a diet of frequent meals, was usually normal. Mild upper respiratory infections with anorexia and/or vomiting rapidly caused hypoglycaemia and severe acidosis.

The functional tests of carbohydrate metabolism yielded the following results: oral glucose test, normal; intravenous glucose test, normal: after 11 minutes the initial true glucose increase had been reduced to half. An oral fructose load ( $2 \mathrm{~g}$. fructose $/ \mathrm{kg}$. body weight) showed normal increase of glucose (from 70 to $93 \mathrm{mg}$./ $100 \mathrm{ml}$.). An intravenous galactose load of $1 \mathrm{~g}$. galactose/ kg. body weight (Schwartz, Ashmore, and Renold, 1957), raised the glucose level from $80 \mathrm{mg} . / 100 \mathrm{ml}$. (fasting value) to $105 \mathrm{mg}$./100 ml.; the highest galactose level was $215 \mathrm{mg}$. $/ 100 \mathrm{ml}$. An intramuscular glucagon test was carried out after fasting for 13 hours (Fig. 1); a normal maximal increase of glucose was obtained after 35 minutes. In the fasting state as well as during the test both pyruvate and lactate levels were normal.

In the laboratory for physical chemistry of the Municipal University of Amsterdam, Dr. Hulsman determined enzyme activities in leucocytes (Table I).

In the laboratory for physiological chemistry of the University at Leuven (Director Prof. Hers) estimations from a liver biopsy were performed (see Table II). The results show that enzymatic activity in leucocytes and liver were all within normal ranges, though the activity of liver phosphorylase was at the lower limit.

The liver glycogen content was above normal, even

\section{TABLE I}

Enzymatic Activities in Leucocytes $(U / g .)^{\star}$

\begin{tabular}{|c|c|c|c|c|}
\hline & & & Patient & Normal \\
\hline $\begin{array}{l}\text { Phosphorylase } \ldots \\
\text { Debranching enzyme system } \\
\text { Acid glucosidase }\end{array}$ & $\begin{array}{l}\cdots \\
\because\end{array}$ & $\begin{array}{l}\cdots \\
\cdots\end{array}$ & $\begin{array}{c}18 \\
0 \cdot 15 \\
1 \cdot 8\end{array}$ & $\begin{array}{c}12-40 \\
0 \cdot 12-0 \cdot 50 \\
1-5\end{array}$ \\
\hline
\end{tabular}

$\star 1 \mathrm{U}(\mathrm{nit})=$ amount of enzyme catalysing conversion of $1 \mu \mathrm{mole}$ substrate under standard conditions per minute.

TABLE II

Biochemical Determinations in Liver Biopsy (U/g.)

\begin{tabular}{|c|c|c|c|c|}
\hline & & & Patient & Normal \\
\hline $\begin{array}{l}\text { Glycogen (\% wet weight) } \\
\text { Phosphorylase } \ldots \\
\text { Glucose-6-phosphatase } \quad \ldots \\
\text { Amylo-1, 6-glucosidase } \quad . . \\
\text { Acid maltase or } \alpha \text {-glucosidase }\end{array}$ & $\begin{array}{l}\cdots \\
\cdots \\
\cdots \\
\cdots\end{array}$ & \begin{tabular}{l|}
$\cdots$ \\
$\cdots$ \\
$\cdots$ \\
$\cdots$
\end{tabular} & $\begin{array}{l}7 \\
16 \\
3 \cdot 4 \\
1 \cdot 3 \\
0 \cdot 61\end{array}$ & $\begin{array}{l}<4 \\
15-30 \\
2-10 \\
1 \cdot 2 \\
0 \cdot 7\end{array}$ \\
\hline
\end{tabular}




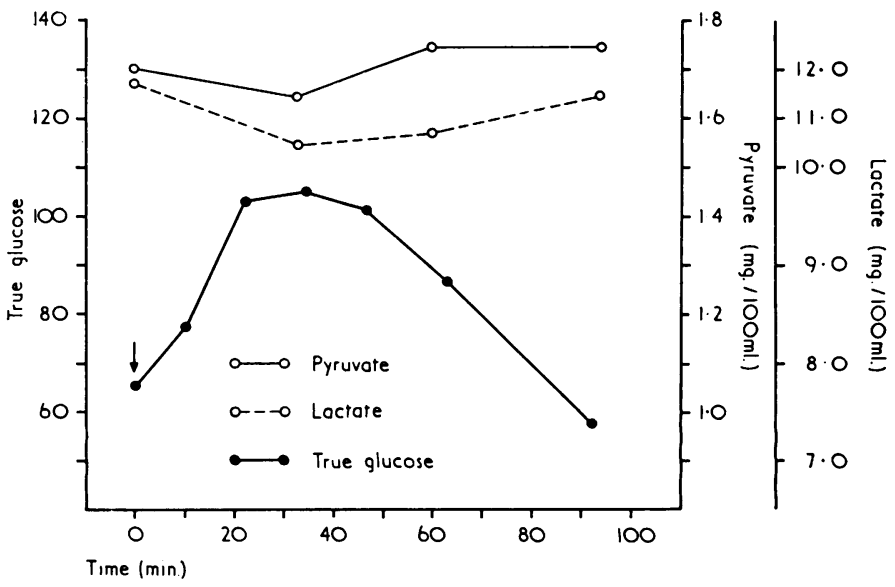

FIG. 1.-Intramuscular glucagon test.

though the biopsy was carried out after a week on a relatively low carbohydrate diet and after fasting for 6 hours.

Dr. Willighagen and Dr. Blok (Dept. of Pathology, University of Leiden) commented upon the pathological aspects of a liver and muscle biopsy. The muscle biopsy was quite normal. Of the liver biopsy (Fig. 2, 3, 4) they reported: 'In the microscopical slides the liver structure appears to be normal. The liver cells are swollen, and are locally vacuolized. In these vacuoles there is sudanophilic material. The liver cells are abundantly filled with PAS positive material, that can be removed by diastase. In the formalin-fixed tissue, this PAS positive material is lost.

'The cells then have the typical image of plant cells.

'Histochemically the activities of glucose-6-phosphatase and phosphorylase are normal. On the basis of the presence of PAS positive material with properties of

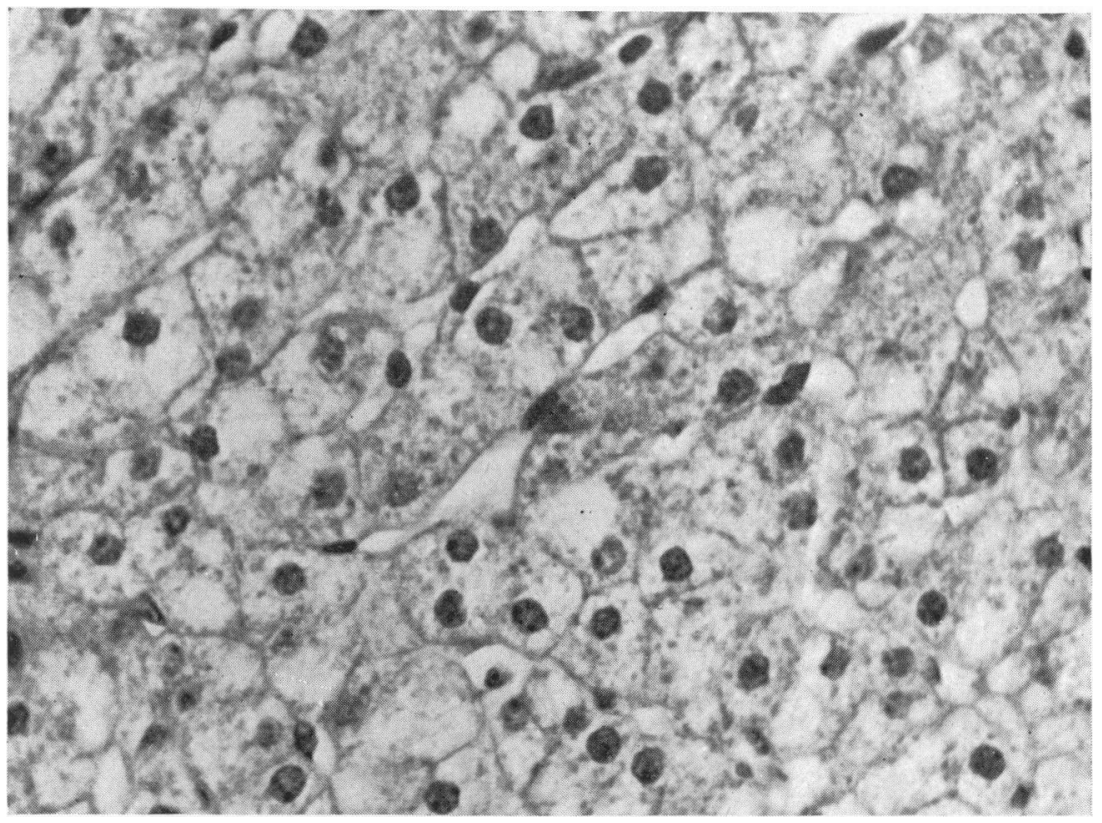

FIG. 2.-Liver biopsy. Vacuolated cells with the appearance of plant cells. $(H$. and $E . \quad \times 300$. 


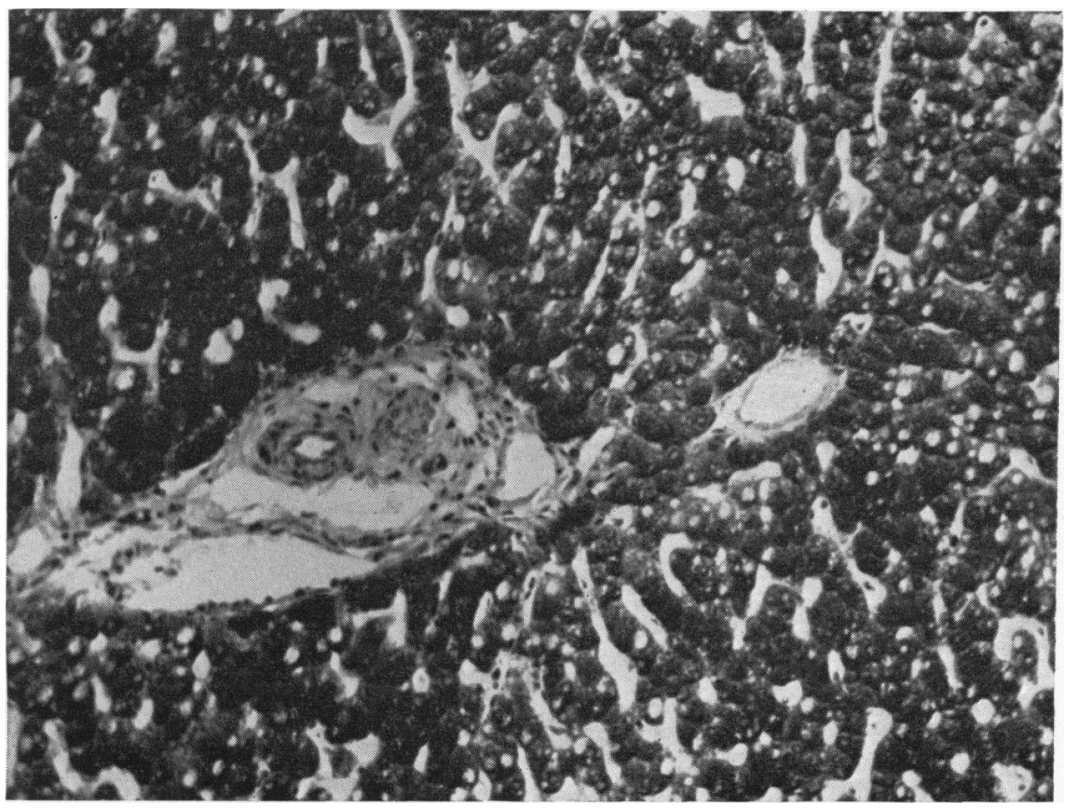

FIG. 3.-Liver biopsy (PAS reaction). Cells packed with glycogen. $(\times 120$.

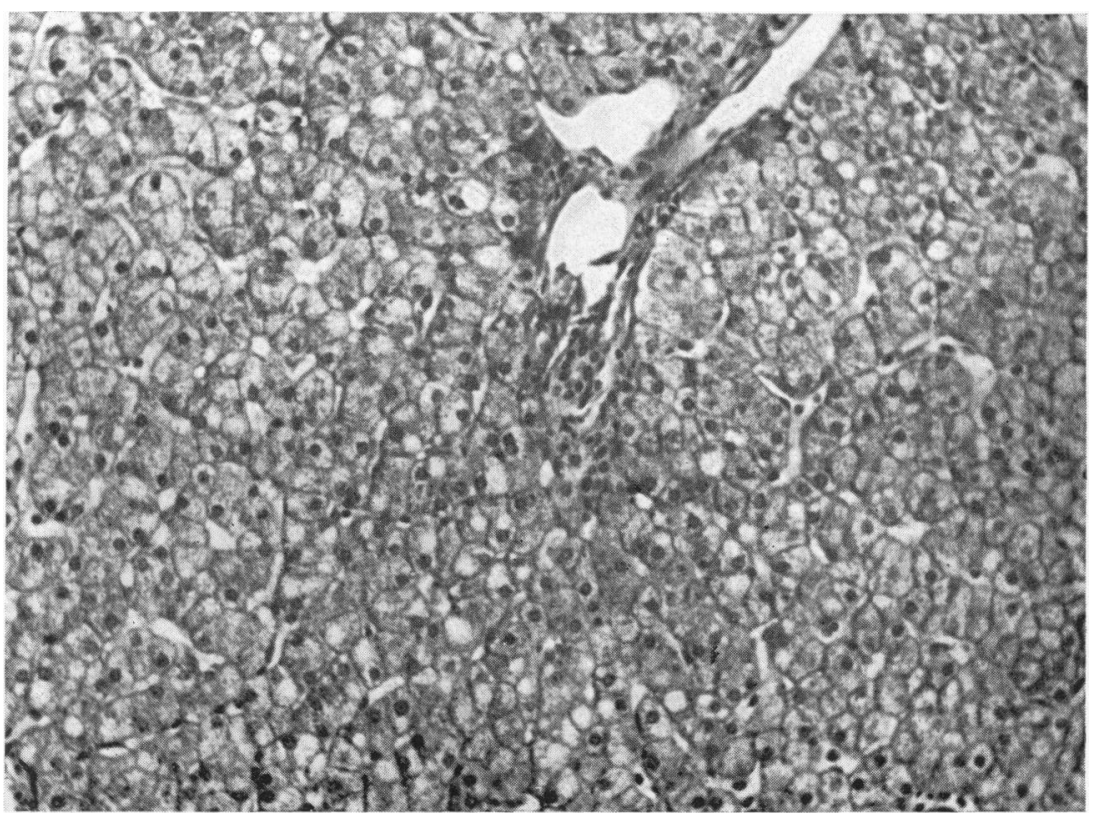

Fig. 4.-Liver biopsy (PAS reaction after diastase treatment). The glycogen is completely digested. $(\times 120$. 


\section{Liver Glycogenosis and Cataracts in a Mentally Deficient Child}

glycogen, we presume that the patient is suffering from glycogen-storage disease.'

Treatment. The patient was treated with frequent meals rich in carbohydrates. As the acidotic attacks came on rapidly the urine was tested daily for acetone. After discharge the mother continued to check the urine, so that impending attacks could be treated quickly. These measures led to a distinct decrease of the frequency of attacks. Pyuria was treated by antibacterial drugs. In this way and by intensive coaching of her parents, this blind girl developed reasonably well. Yet she still functions at a high imbecile level. The rate of linear growth has increased. The growth between the 12th and 27th month was $11.5 \mathrm{~cm}$. (normal about $14 \mathrm{~cm}$.); between the 27th and the 36th month she grew $12 \mathrm{~cm}$. /year (normal about $9 \mathrm{~cm}$.), and between the 36th and 52nd month $10.5 \mathrm{~cm}$./year (normal about $7 \mathrm{~cm}$.).

\section{Discussion}

The clinical picture (hepatomegaly, hypoglycaemic episodes with severe acidosis, spontaneous acetonuria), as well as the microscopical appearances of the liver and the amount of liver glycogen, leave little doubt that the patient's illness belongs to the group of glycogen storage diseases. Clinical classification, however, presents difficulties. Type II or Pompe's disease is easily ruled out, because of the clinical symptoms, the absence of heart enlargement, and the age of the child. In type IV, abnormal glycogen leads to liver cirrhosis, and the latter dominates the clinical picture; and hypoglycaemia does not occur. Type $\mathrm{V}$, which shows storage of normally structured glycogen in the skeletal muscles and in which the only clinical symptom is aching in the muscles during work, is also ruled out.

Glycogen synthetase deficiency causes very low liver glycogen, and can be excluded here. A diagnosis of either type I, III, or IV can be rejected on the following grounds. There is no sign of type I whatever: galactose and fructose tests normal; lactic acid and pyruvate levels not increased. And lastly, there is a normal glucose-6phosphatase level in the liver. The normal increase in the blood glucose level during a glucagon test does not fit with type III, though the test could not be carried out after prolonged fasting. The debranching enzyme system in liver and leucocytes also proved to be normal. In type VI, patients show a lack of liver phosphorylase. In our patient, leucocyte phosphorylase was normal, whereas liver phosphorylase was at the lower limit of normal, but not as low as is usual in type VI.

In 1965 Hug, Schubert, and Schwachman described a girl with progressive spasticity and mental deterioration; in the liver they found varying amounts of glycogen which, however, were always above normal (8-17\% wet weight), and a fluctuating but, on the average, lowered phosphorylase activity $\left(5 \cdot 8-17 \mathrm{U}^{\star} / \mathrm{g}\right.$. tissue). No acidotic or hypoglycaemic attacks occurred. Lipaemia was also normal. This type of glycogenosis has been called type VIII.

These authors proved, with many repeated liver biopsies, that adrenaline and glucagon stimulated phosphorylase to normal activity in vivo, from which they concluded that not only was phosphorylase present, but also that the activating enzyme system, which is stimulated by glucagon and adrenaline, could not be the cause of the impairment of glycogen liberation from the liver. The child excreted cathecholamines in amounts that were 2 to 6 times higher than normal. Therefore, they put forward the hypothesis of a disorder in adrenaline and noradrenaline metabolism, with secondary glycogenosis caused by insufficient phosphorylase activation.

In $1966 \mathrm{Hug}$ et al. defined, as type IX, another case of liver glycogenosis with strongly reduced phosphorylase activity. This activity could be increased in vitro by adding an activating system. In vivo adrenaline and glucagon did not increase this activity, though the glucagon test caused a normal rise in blood glucose. This child, who showed a distinct hepatomegaly, had a normal excretion of cathecholamines, development was not retarded, and only mild hypoglycaemic attacks without acidosis occurred.

Our patient shows some criteria which distinguish both of these types from each other: liver glycogenosis with lowered liver phosphorylase activity and a normal glucagon test. As in type VIII, our patient is mentally deficient (without spasticity, however) and has a moderate hepatomegaly. Her normal cathecholamine excretion corresponds better with type IX. The strong tendency to acidosis is not found in either of these types.

Possibly our patient's illness should be regarded as a variant of the forms of liver glycogenosis described by Hug et al. (1965), which are still hard to define at the moment because of the very small number of patients reported. They are characterized by an increased amount of liver glycogen with clinical and histological evidence of liver glycogenosis, and with normal enzyme tests except for low normal activity of liver phosphorylase. The

* $1 U$ (nit) = amount of enzyme catalysing the conversion of 1 umole of substrate under standard conditions per minute. 
classification is still speculative. It is also not known if the cataracts belong to the picture.

\section{Summary}

A mentally retarded girl is described, born of consanguineous parents, and showing congenital cataract and blindness. From the age of 8 months the patient had frequent attacks of hypoglycaemia with marked acidosis. The clinical picture, and pathological and biochemical examination of a liver biopsy led to a diagnosis of liver glycogenosis. The usual tests for carbohydrate metabolism and enzymes in leucocytes were normal. Enzyme investigations in a liver biopsy specimen showed only a low normal activity of liver phosphorylase, other enzymes being normal. The significance of these findings is discussed in relation to the recent published reports.

\author{
REFERENCES
}

Brante, G., Kaijser, K., and Ockerman, P. A. (1964). Glycogenosis type I (lack of glucose-6-phosphatase) in four siblings. Acta paediat. (Uppsala), Suppl. 157.

Cori, G. T. (1954). Glycogen structure and enzyme deficiencies in glycogen storage disease. Harvey Lect., 48, 145.

van Creveld, S. (1928). Over een bijzondere stoornis in de koolhydraat-stofwisseling in de kinderleeftijd. Ned.Maandschr. Geneesk., 15, 349.

Hers, H. G. (1965). Inborn lysosomal diseases. Gastroenterology, 48, 625.

Hug, G., Garancis, J. C., Schubert, W. K., and Kaplan, S. (1966). Glycogen-storage disease, types II, III, VIII and IX. Amer. 7. Dis. Child., 111, 457.

- Schubert, W. K., and Schwachman, H. (1965). Imbalance of liver phosphorylase and accumulation of hepatic glycogen in a girl with progressive disease of the brain. F. Pediat., 67, 741 .

Illingworth, B., and Brown, D. H. (1964). Glycogen-storage diseases types III, IV, and V. In Control of Glycogen Metabolism, Ciba Foundation Symposium, ed. W. J. Whelan and M. P. Cameron. Churchill, London.

Lewis, G. M., Spencer-Peet, J., and Stewart, K. M. (1963). Infantile hypoglycaemia to inherited deficiency of glycogen synthetase in liver. Arch. Dis. Childh., 38, 40.

Schwartz, R., Ashmore, J., and Renold, A. E. (1957). Galactose tolerance in glycogen storage disease. Pediatrics, 19, 585.

Thomson, W. H. S., Maclaurin, J. C., and Prineas, J. W. (1963). Skeletal muscle glycogenosis: an investigation of two dissimilar cases. F. Neurol. Neurosurg. Psychiat., 26, 60. 